\title{
Professional Development Needs of Private and Public High Schools EFL Teachers in Erbil-Kurdistan
}

\author{
Mawdud Ibrahim ${ }^{1} \&$ Aziza Kavlu ${ }^{2}$ \\ ${ }^{1 \& 2}$ English Language Teaching Department, Faculty of Education, Tishk International University, Erbil, \\ Iraq \\ Correspondence: Aziza Kavlu, Tishk International University, Erbil, Iraq. \\ Email: aziza.kavlu@tiu.edu.iq
}

Doi: 10.23918/ijsses.v7i3p191

\begin{abstract}
Due to the importance of professional development in the improvement of teaching and education, and the importance of English as a language and subject of study in Erbil, this study focused on the needs for professional development of English teachers. The present study also investigated teachers' opinions about their needs for professional development. The study also attempted to explore other issues related to the professional development of teachers of English in Erbil such as benefits of professional development programs, state of professional development programs, stages of applying for professional development programs and problems in professional development programs. 36 English language teachers participated in a survey. The survey results demonstrated that a great number EFL teachers are aware of the importance of professional development. However, lack of resources and opportunities are some of the major reasons which prevent them to participate in professional development activities. The present study attempts to reveal what EFL teachers think about their professional development and what kind of difficulties they face in pursuing their goals.
\end{abstract}

Keywords: English Teachers' Profile, Professional Development, Teacher Quality, EFL Teachers

\section{Introduction}

In our current age, English has become the global language, and EFL teachers more than ever need to prepare themselves regularly to better respond to the ever-changing conditions of society. Professional development is defined in several ways by several researchers. For instance, according to Hargreaves and Fullan (1992) professional development is the teacher's commitment to inquiry and a continuous lifelong learning process by emphasizing the continuity of the unlimited aspects of learning. In a similar but more social sense Fletcher and Zuber-Skerritt (2008) defines professional development as a costly part of the government, professionals, and individuals which should be paid to comply and respond to continuous changes. This means that training of teachers is not limited to degree courses, but to a continuous educational process. From a different perspective, Birman et al. (2000) points out that professional development is effective only by providing more learning and development opportunities to improve teaching practice and ability. In other words, in addition to social and lifelong aspects, teacher professional development has also an individualistic and skill-based aspect.

In the past two decades, the policy of introducing English as a foreign language (EFL) in elementary education has been implemented around the world (Butler, 2015). As teachers are indispensable in 
implementing policies, there is a need for fostering teaching practices by means of professional development (PD) (Copland \& Garton, 2014; Enever, 2014). However, the identification of teacher needs concerning PD has not received enough attention. Previous research has focused on expounding various challenges encountered by teachers in the classroom (Chen \& Cheng, 2010) and identified some pedagogical concerns, including implementing communicative approaches (Butler 2005), assessing learning outcomes (for example Wang, 2002), incorporating corrective feedback (for example Zhao, 2009), using code-switching for instruction (Qian et al., 2009) and examining the practical knowledge of teachers (Chou, 2008). On the other hand, other studies focused more on the types of PD programmers/activities, rather than specifying the specific needs of teachers (for example Kabilan \& Veratharaju, 2013; Chien 2014). To further clarify the improved PD practice and help enhance teachers' teaching practice, it is necessary to research to determine teachers' needs for PD in middle school EFL.

\section{Purpose of the Study}

The aims of the current research are to:

- Identify instructors' perceptions of professional development and its effectiveness in ErbilKurdistan.

- Recognize the English supervisors, administrative perceptions on professional development in private and public high schools in Erbil_ Kurdistan and the benefits of it to develop students' interest.

- Provide theoretical and practical suggestions in the field to teachers and administrators.

- Recognize EFL teachers and EFL supervisors in Erbil private and public schools about professional development programs and problems they face.

\section{Research Questions}

This study seeks to answer the following questions:

1. What is the status of professional development programs in Erbil?

2. What are the needs of high private and public schools of EFL teachers to be professional in Erbil?

3. What are the most common professional development problems that EFL teachers encounter in Erbil private and public schools?

4. What are the professional development opportunities available for high school EFL teachers in Erbil Kurdistan?

5. In which stage of teaching EFL teachers need a professional development program?

6. To what extent EFL teachers are familiar with PD programs in high private and public schools in Erbil? 


\section{Literature Review}

\subsection{EFL Teachers' Professional and Specialist Needs}

This part includes two main parts: first, the professional needs of EFL teachers related to teaching methods, and professional needs of EFL teachers related to English fluency. Then, some captions are related to this, such as the definition and importance of professional development, checking the professional level of some EFL teachers in certain countries, and determining the professional ability of EFL teachers.

\subsection{Teachers' Professional Needs}

The professional development of teachers is essential to the successful improvement of education. The professional development of teachers is the position of future and experienced teachers and the new challenges they will need to face to guide all students to a higher level of learning and development. The development of the professional knowledge of EFL teachers is considered as a continuous learning process, during which teachers participate voluntarily to learn how to best adjust their teaching to meet the learning needs of students.

Martinet et al. (2001) described professional development as a continuous process in which individuals are trained to practice specific occupations. People will not become skilled practitioners after completing the training. On the contrary, they have gradually accumulated experience and continuously developed their profession over the years, reaching a certain professional level in some cases. Because of the complexity of the situation and the constant change of professional background, this major is a dynamic and continuous learning process.

According to Ali (2002) the professional development of teachers' teaching knowledge is defined as a continuous process, including activities that promote professional development. It may include seminars, independent reading and research, meetings, and consultation with peers and experts. Rahimi (2007) described teachers' professional knowledge as learning and teaching and introducing them to teachers through a series of courses on content knowledge and teaching methods.

According to Badawi (2009) teaching knowledge refers to teachers' knowledge of basic teaching content, such as learning theory, teaching methods, curriculum design, assessment techniques, and related management issues. Teaching knowledge also refers to EFL teachers' knowledge of four specific teaching areas, namely: learner feedback, learner strategies, authentic materials, and alternative assessments. There seems to be three essential components (triangle of success) that contribute to the success of EFL teachers: 


\section{Language}

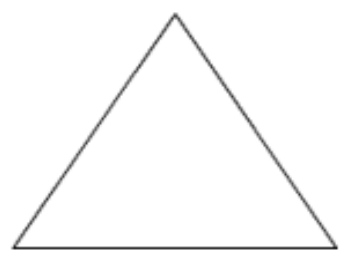

Techniques

Culture

Figure 1: Success triangle of EFL teachers (Source: Millrood, 1999)

Professional teachers must:

- Be strict towards the class.

- Be kind towards individuals.

- Help students overcome learning problems even if it requires sacrificing one's own time after classes.

- Empathize with the learner.

- Be always available, even on the telephone for consultations.

- Translate the material into a digested form (Millrood, 1999, p.6).

Teachers need to study their teaching environment, pay special attention to their students, their materials, and their teaching in order to make difference in their learning (Mart, 2013a; Mart, 2013b). Michael (1997, p.13) determines that teachers need to study their teaching methods and overall classroom style.

- Do they incorporate various ways that students can learn the language that is modeling, practicing, or presenting, to appeal to a variety of learning styles and strategies?

- Does teaching allow learners to approach the task at hand in a variety of ways?

- Is training implicit, explicit, or both? By audiotaping or videotaping one's classroom teaching an instructor may objectively consider just what was, taught and modelled, and how students responded and appeared to learn.

- Do they allow students to work on their own and learn from one another?

- As they circulate in class, are they encouraging questions, or posing ones relevant to the learners with whom they interact?

Effective professional English educators do not acquire teaching content knowledge randomly, but develop the knowledge base through reading, reflecting, and practicing the strategies and techniques 
described and perfected by many scholars, researchers, theorists, and other practitioners in the specific field. Martinet et al. (2001) states that some people believe that professional competence is applied in a professional environment in real life. It is based on a set of resources and the ability to mobilize resources when professional actions are required, this process from simple to complex will be successful and effective.

An effective teacher should be able to make many choices in terms of methodology, subjects, educational technology, attractive aids, strategies, activities, and materials. The more a teacher learns, the better he or she can monitor his/her teaching. Therefore, teachers must continue to develop their abilities and obtain lifelong professional development.

\subsection{EFL Teachers' Specialist Needs}

EFL teachers need to be able to deal with many related skills to teach effectively. They must be proficient in listening, speaking, reading, and writing. Similarly, English foreign language teachers must have crosscultural competence, which means they must understand their own culture and English culture to be familiar with the similarities and differences between them.

The teacher's language ability is defined as the teacher's ability to use the target language effectively in all skills (listening, speaking, reading, and writing) (Al-Mekhlafi (2007; Mart, 2012; Mart, 2018). English proficiency is the backbone of the teaching profession of non-native EFL teachers. Rahimi (2007) pointed out that language ability is one of the most basic characteristics of excellent language teachers, and it has become the basis of professional confidence for non-native English teachers.

Al-Mekhlafi (2007, p.11) divides specialist competencies into two parts:

1- Basic Level Competencies: It is characterized by being able to use the language in a highly predictable and familiar situation. The ability to ask and answer questions, participate in, write and understand simple, familiar and common dialogues or texts related to various topics. These questions are mainly related to their surrounding environment, but there are obvious difficulties.

2- Higher Level Competencies: Characterized by being able to use the language proficiently. High-level ability can complete various communication tasks related to familiar or new topics. Those proficient at this level can talk, write and understand current, past, and future events. He can organize their thoughts in the appropriate coherent and coherent discourse, whether written or spoken.

Zhou (1999, p.3) ensures that the proficiency of the target language includes the teacher's understanding, the ability to speak, accurate pronunciation, read and write English, knowledge of foreign customs, cultural and intercultural communication, the essence of language acquisition, linguistic knowledge, the ability to maintain and complete basic communication tasks. Teachers should be open to foreign cultures, share his/her understanding of the differences between foreign cultures and themselves with students, and demonstrate this knowledge in teaching. 


\section{Method}

\subsection{Type of Research Methodology}

Descriptive analysis methods are used to describe and analyze the information obtained from the survey to explore the teachers' opinions. Descriptive research is defined as "research that describes a set of characteristics or behaviors in digital form (Brown \& Rodgers, 2002, p.117). Research also interprets data in words in case of qualitative data (Maykut \& Morehouse, 1994). In this study, the researcher used quantitative data that is taken from the survey numerically.

\section{Participations and Research Setting}

The participants teach in private and public schools in Erbil. They have different backgrounds in teaching. Most of the teachers were young and fresh graduate and they wish to know up-to-date knowledge about professional development programs. Most of the English teachers in the participants who were given the survey were males (30), and some of them were females (6). The researcher tried to investigate the opinions of both private and public teachers in Erbil. The participants had teaching experiences from one year to thirty years. The teachers came from different backgrounds and have varying qualifications like diploma, bachelor, or post-graduate diploma. The participants were from different nations (5 Turkish, 1 British, 3 Arabic, 27 Kurdish).

\section{Instrumentation}

The survey was the main data collection instrument for this study. The survey was in English language. Teachers in Erbil who work at private and public schools filled in the survey.

\section{Data Analyses}

In this study the researcher used Google document and analytic to analyse the obtained data.

\section{Findings and Discussions}

The findings and data collected using survey are discussed and analyzed in this section about the research questions and the review of the literature. The study explored ten different questions about professional development needs for teachers of English in Erbil private and public schools.

\subsection{The Status of Professional Development Programs}

36 teachers answered a question in the survey about the availability of professional development programs in Erbil, in the first question. While (33.3\%) of the teachers responded that they fairly disagree that professional development programs are available in Erbil, (30.6\%) agreed that such programs exist in Erbil. The number of teachers who strongly disagreed were more in the statements. Just a small number of them said that they strongly agree with having professional development programs in Erbil. This survey showed that most EFL Teachers do not have information about professional development programs in 
Erbil. Figure 1 illustrates whether the participants agree that professional development programs are available in Erbil private and public schools.
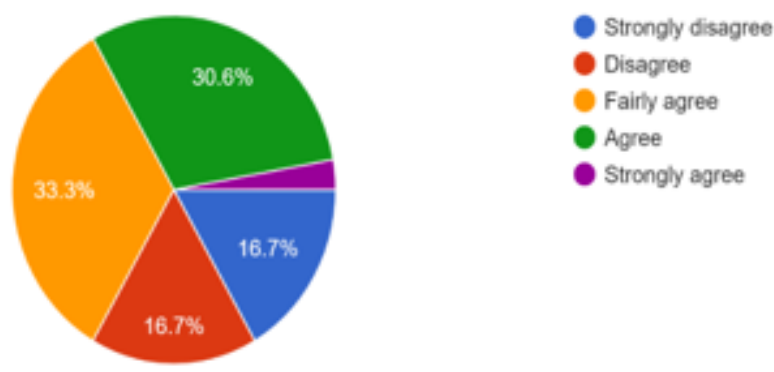

Figure 1: Are there enough programs for developing EFL teachers in schools $(n=36)$

\subsection{The Neediness of EFL Teachers}

The EFL teachers in Erbil private and public high schools answered a question which was about the need for professional development programs in Erbil schools in the second question. (61.1\%) of the participants said that they strongly agree that they need professional development programs and activities. While (19.4 $\%$ ) of the participants responded that they need to have a kind of professional development activity in Erbil, (13.9\%) fairly agreed that this need should be cared about. In this question, there are no teachers who responded that they do not need to have PD programs and activities in Erbil.

This question in the survey showed that most EFL teachers are willing to have professional development programs in Erbil and they want to participate there. Figure 2 shows whether the participants need professional development programs in Erbil private and public schools.
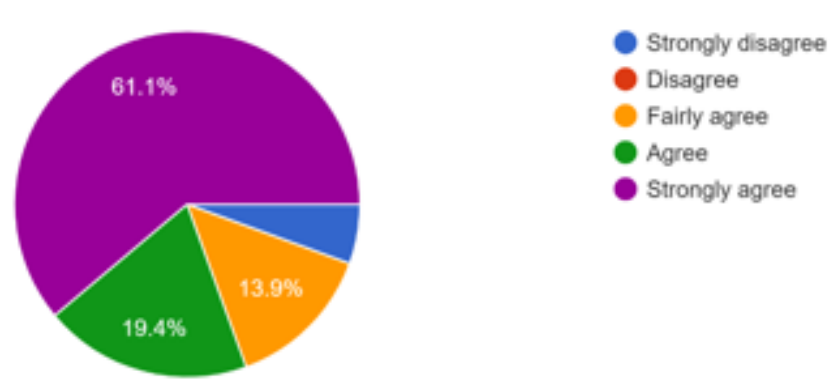

Figure 2: EFL teachers' neediness of PD programs in Erbil $(n=36)$ 


\subsection{Teaching Areas That Require Professional Development}

In question 3, the participants were asked about their needs in their professional development and they were provided four options (they were allowed to select more than one option). (88.2\%) of the participants selected teaching methods as their major need in their professional development. (41.2\%) selected classroom management, (41.2\%) selected subject material area, and (41.2) selected material development as a need in their professional development (Figure 3).

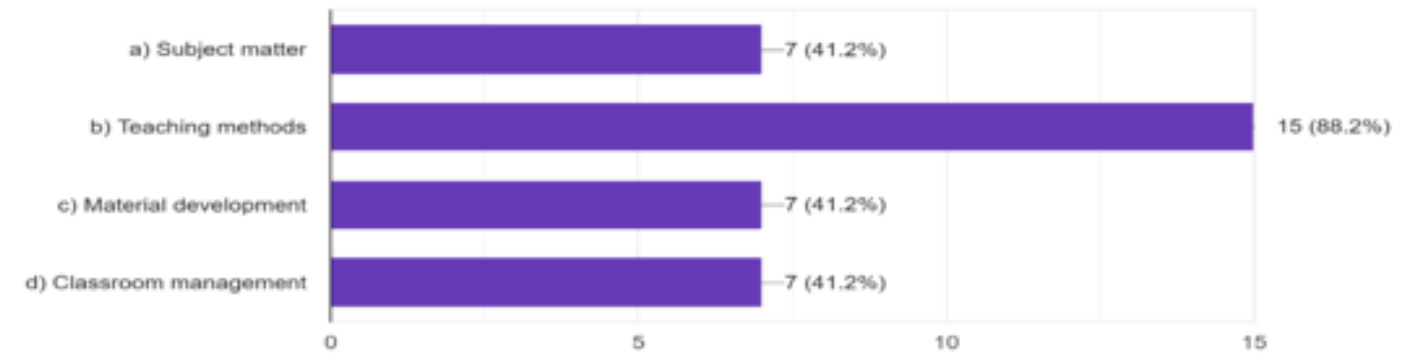

Figure 3: The areas the participants selected to improve for their professional development $(n=36)$

\subsection{Professional Development Problems}

In question 4 the participants were asked about the reasons which would prevent them from pursuing their professional development. Unavailability of professional development programs was the most prevalent reason which was chosen by (64.7\%) of teachers. Second, the lack of resources was chosen by (47.1\%) of teachers. The expenses of professional development activities was chosen by (35.3\%) of teachers. While lack of time was chosen by (29.4\%) of teachers, the location of the professional development programs was chosen $(23.5 \%)$ of teachers.

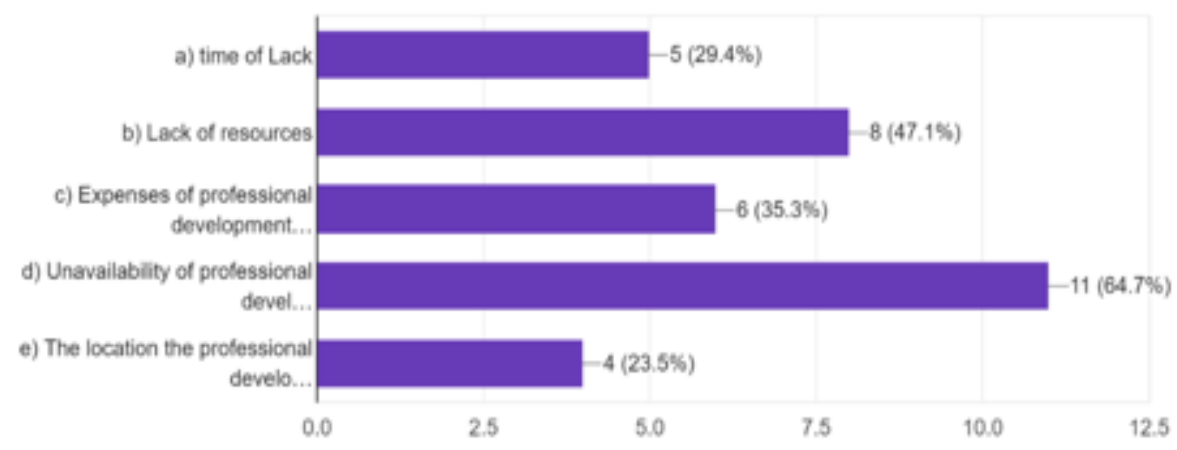

Figure 4: Reasons which prevent teachers from pursuing professional development in Erbil schools $(\mathrm{n}=$ 36) 
The unavailability of professional development programs which was mentioned by $(64.7 \%)$ of teachers may suggest that teachers are not being provided with adequate training and professional development activities by their administrators. Administrators should create a platform to discuss and plan the professional development of their teaching staff (Engstrom \& Danielson, 2006; Öztaş, Özdemir, \& Mart, 2017). It should be noted that administrators can encourage their teachers to pursue professional development programs by reducing their working load at schools, providing resources for them and even covering some of their expenses to pay for professional development programs.

\subsection{Professional Development Opportunities}

EFL teachers should take care about what type of professional development is available for them to work for being professional during their professional careers. There are some international programs and online courses available for EFL teachers' professional developments in Erbil private and public schools. The researcher was interested in finding out about teachers' opinions concerning availability of these programs like (TEFL, TESOL). For that reason question five was about whether teachers were aware of availability of international programs and online courses in Erbil for EFL teachers.

(44.4\%) of the teachers said that there are not enough number of available international courses in Erbil schools. While $(27.8 \%)$ of the participants fairy agreed that Erbil schools provide them professional development programs, $(27.8 \%)$ of them agreed that they can find opportunities to enhance their professional development in their schools. We see that in total $(55.6 \%)$ of the participants can find an opportunity in their schools to participate in an international professional development program. However, $(54.4 \%)$ of the participants state that they do not have an opportunity to participate in an international program in their schools.
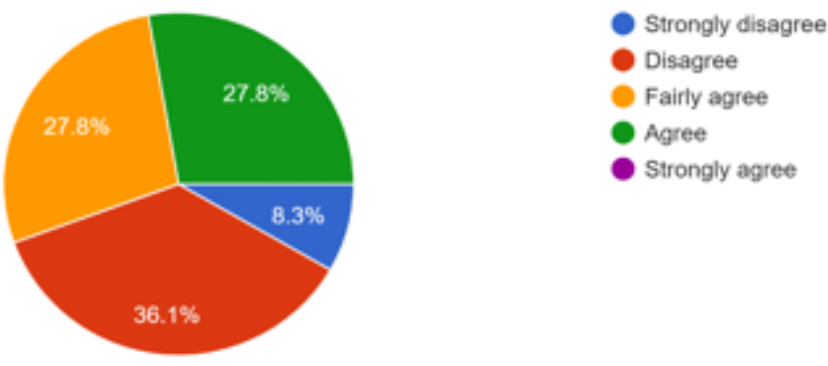

Figure 5: Availability of international programs and online courses in Erbil for EFL Teachers $(n=36)$

\subsection{Encouraging and Motivating Factors}

In question 6, the teachers were asked what would motivate or encourage them to pursue professional development. Five choices were given to the participants and they were allowed to select more than one option. They were even allowed to add reasons other than the ones in the choices. It was found that (70.6\%) of the teachers indicated that learning new strategies about language teaching would motivate 
them to continue with their professional development. (58.8\%) of them responded that gaining selffulfilment and job satisfaction would motivate and encourage them for professional development. Career advancement and students' progress which was chosen by $(52.9 \%)$ of the teachers were also considered as reasons which would motivate them. Finally, (17.6\%) of the teachers stated that getting a raise would motivate them for professional development.

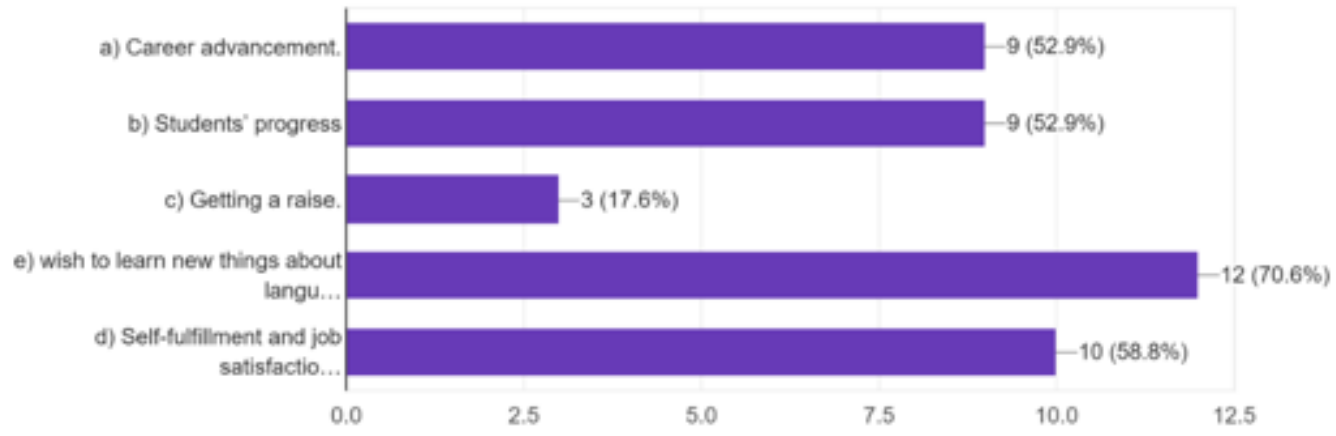

Figure 6: Reasons which would motivate and encourage teachers for pursuing professional development

$$
(\mathrm{n}=36)
$$

As most of the participants chose learning new strategies about language teaching may suggest that a great number of the teachers are really interested in improving their professional development. Also, when the results are examined it is clearly seen that the majority of the teachers in the survey responded that students' progress, job satisfaction, self-fulfilment, and career advancement are major reasons for pursuing professional development. These results indicate that the teachers have the desire for professional development. In question 6, the teachers were asked who would benefit from these professional development programs more; the teacher, the students, the school or institution. Results revealed that (82.4\%) of the participants responded that teachers would benefit from these programs more than the others. While $(76.5 \%)$ stated that the community would benefit from these programs, $(64.7 \%)$ responded that the school or institution would benefit most from the professional development of teachers.

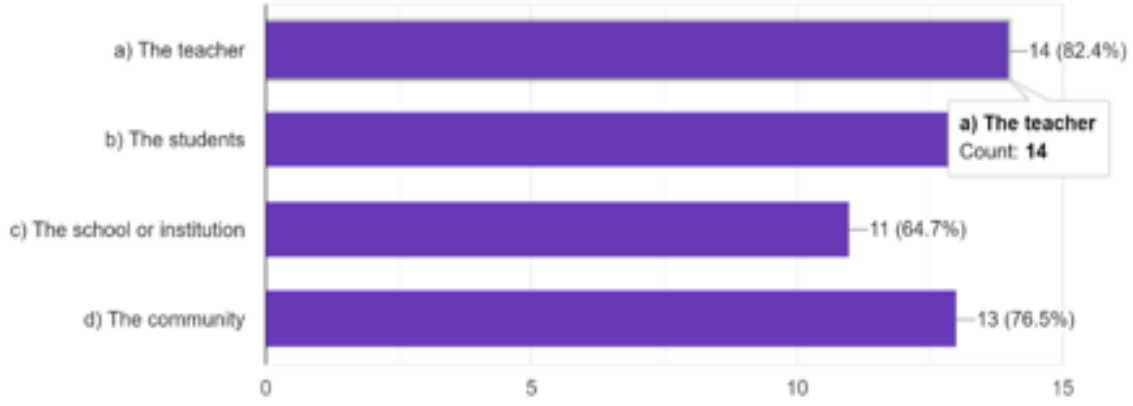

Figure 7: Who would benefit more from professional development programs $(n=36)$ 
These results indicate that most of the teachers believe that professional development programs are useful for teachers and students more than others. This shows that the majority of the teachers are aware of the potential influence of these programs on their professional development and their students' improvement.

\subsection{Suitable Stages for Applying for PD Programs}

Determining the right time for professional development program is of huge importance. Therefore, teachers need to know when to apply for these programs in their careers. In question 7, the teachers were asked when they need these professional development programs during their careers.

(38.9\%) of the teachers said that teachers need professional development programs in Erbil schools in all stages in their careers, and (36.1\%) of them strongly agreed that they need these programs in all stages in their careers. In other words, $75 \%$ of the participants agreed or strongly agreed that they need these programs throughout their careers. (19.9\%) fairly agreed that they need these programs in all stages in their careers. We see that all of the participants responded that they needed these programs in all stages of their careers. These results clearly show that the participants are well aware of their professional development in all stages of their teaching experience.

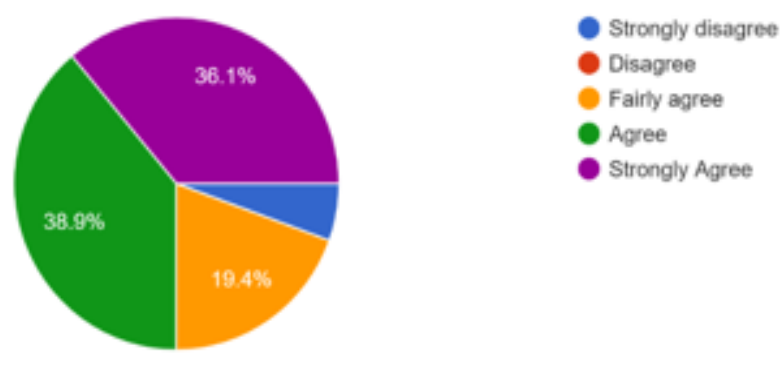

Figure 8: Applying for professional development activities in different stages in Erbil $(\mathrm{n}=36)$

\subsection{The Familiarities of PD Programs}

Familiarity EFL teachers with PD is very necessary and in the present study the researcher aimed to reveal whether they are familiar with professional development programs or not. Regarding this issue, he asked a question whether the participants are familiar with PD. In question 8, (44.4\%) of the teachers fairly agreed that they were familiar with PD Programs, and (30.6\%) said that they are not familiar with PD programs and activities. The reason for this could be the lack of opportunities of participating professional development programs in their schools. Only (16.7\%) agreed that they are familiar and they know about professional development programs. 
This question reveals that most EFL teachers are not familiar with professional development programs or they have little information about them. For their responses we might conclude that teachers are not provided enough opportunities in their schools for professional development.
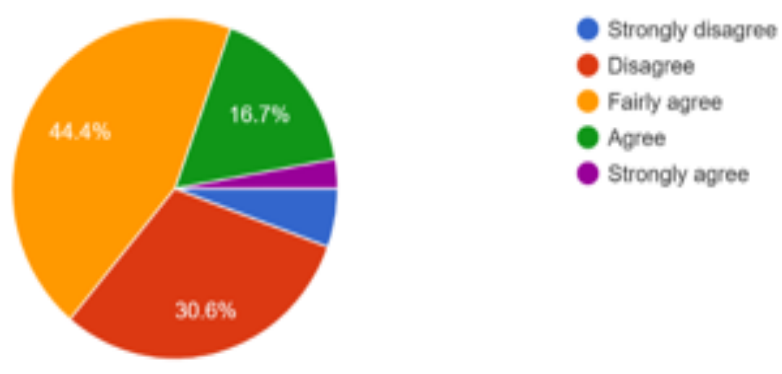

Figure 9: Are EFL teachers familiar with professional development programs in Erbil? $(\mathrm{n}=36)$

In question 9, the researcher investigated what professional development means for EFL teachers. They were given some options and were allowed to select one than more choice. (100\%) of the teachers considered PD as searching on the internet and consulting books for new teaching ideas. This type of PD is a teacher-initiated endeavour.

While $(70.6 \%)$ of the teachers considered PD as training programs organized by schools. $(58.8 \%)$ of the teachers regarded PD as training programs organized by the Ministry of Education. And (41.2\%) considered PD as attending workshops organized by other teachers. (29.4\%) thought that PD is reading scholarly journal articles about language teaching. (29.4\%) considered PD as observing classes of other teachers.

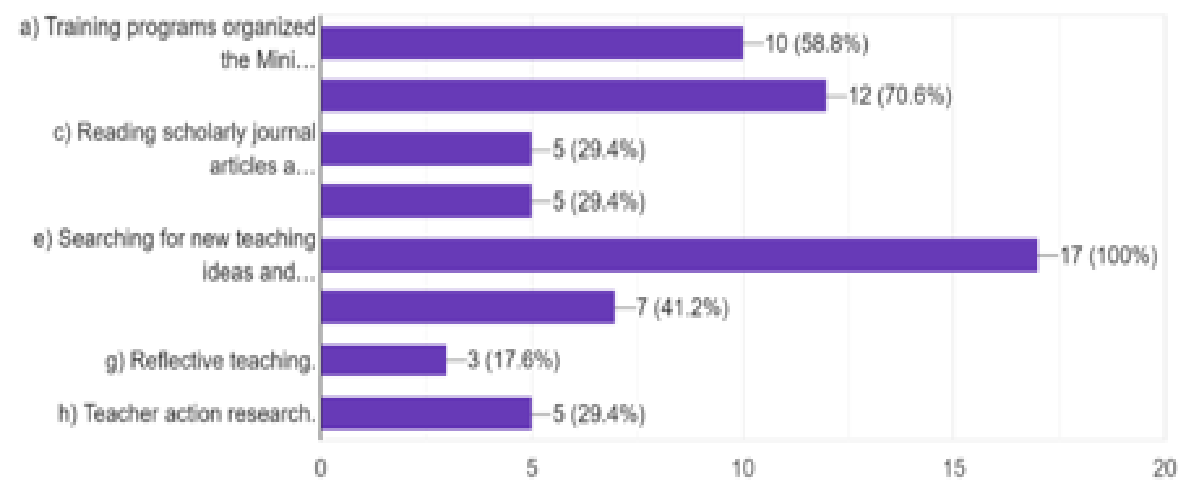

Figure 10: The meaning of professional development for EFL teachers $(n=36)$ 
Although it is known that action research and reflective teaching are important tools of teacher development (Johnson, 2002; Mann, 2005; Nunan, 2001), only a small number of teachers considered them as types of professional development. It is possible to conclude that teachers are not aware that these tools are effective in teaching efficiency and skills. It goes without saying that, teachers should be introduced about these tools to foster their teaching competence. Similarly, in order to enhance their professional development teachers attention should be drawn to these tools.

\subsection{Selection of Professional Development Programs}

Question 10 addressed the selection of professional development programs. It was found that (41.2\%) of the teachers select their professional development activities themselves and (58.8\%) of them responded that professional development programs were selected by their supervisors for them. The schools play the major role in selecting the training programs because $(68.7 \%)$ said that their school's administrations selected the programs for them.

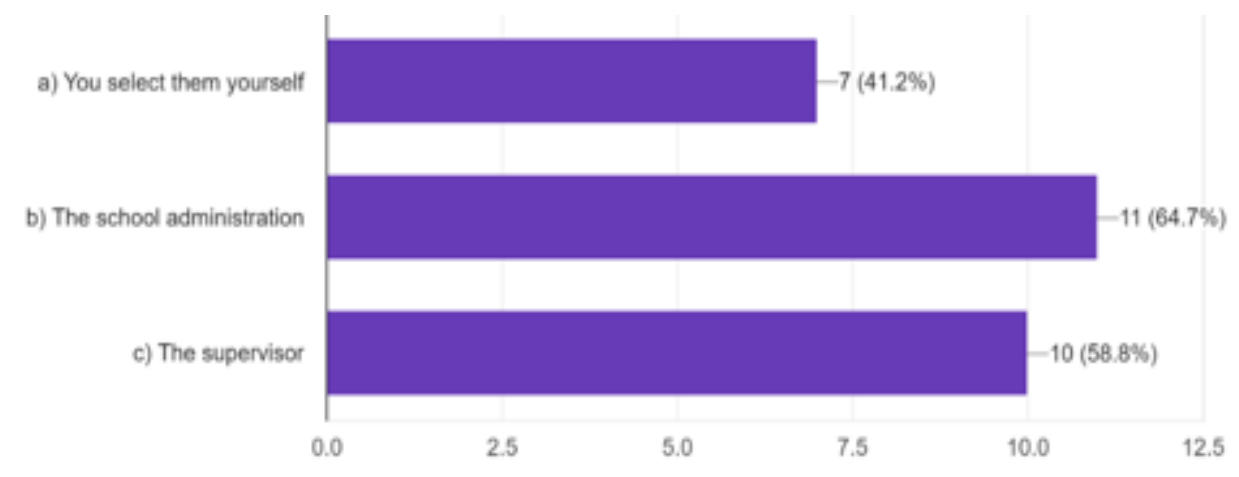

Figure 11: Who selects professional development activities for teachers at schools $(n=36)$

It is possible to conclude that professional development programs are mostly determined by school administrators. It should be noted that teachers and supervisors should be also included in making a decision about the types of professional development. The needs of teachers should be determined by themselves.

\section{Discussion}

The aim of this study was to investigate the needs of EFL teachers for professional development in Erbil private and public schools. It also investigates what EFL teachers need to enhance their professional development. This part of the study endeavors to reveal the findings of the study. And it summarizes the findings of the study according to their relations to the research questions. 


\subsection{Status of Professional Development Programs}

Professional development is essential for teachers. When the survey questions were examined, it is true that in Erbil EFL teachers are aware that they need to enhance their professional development. However, it is understood that schools do not provide enough opportunities for teachers in terms of professional development. Although, most of the participants in this study responded in the survey that they need professional development activities at schools, administrators do not provide opportunities for them to pursue their professional development. Moreover, the teachers responded that these activities hold an important place in their careers to better their teaching skills. The study revealed that both novice and experienced teachers are in favour of participating professional development activities throughout their careers. In other words, professional development is a need for them in all stages of their careers.

\subsection{Problems in Professional Development Programs}

One of the areas the current research focused on was problems in professional development programs. The findings revealed that lack of resources and time, unavailability of professional programs were major problems for most of the participants. It is true that teachers need enough time and resources for their professional development. Unless these tools are not provided, it is useless to discuss about professional development. The participants in the present study responded that these problem they encounter prevent them from professional development. As teachers cannot find enough opportunities, they cannot foster their teaching competence. The findings showed that as a great number of the teachers in the study face problems concerning their professional development, student learning may be negatively affected.

\subsection{Needs of Professional Development Programs}

Professional development programs should be designed to enable teachers to become more skilful in teaching. Teachers should be equipped with the necessary tools and skills to meet the needs of the students. For instance, curriculum development, classroom management skills, developing materials, implementation of new teaching skills in classes, integrating technology into classroom teaching are necessary tools for effective teaching. With this in mind, teachers need these tools to make difference in student learning. The findings showed that the participants were aware of the benefits of professional development activities for their professional development. Therefore, these tools should be included in professional development activities.

\subsection{Stages of Applying for Professional Development Programs}

Professional development is an ongoing process. Teachers from the first day of their teaching experience need to develop their teaching competence. The findings of the study revealed that the participants were well aware that in all stages of their teaching experience, they need to enhance their professional development. In order to meet the needs of their students, and to become committed teachers, they should care about their professional development. Also, for job satisfaction professional development programs hold a significant place. 


\section{Conclusion}

Since professional development is essential to improve education, more attention is needed. In order to increase the quality of teaching and learning, teachers should be equipped with the necessary tools and skills. Thus, teachers should be motivated and encouraged for professional development. Teachers should be provided enough professional development opportunities to foster their teaching competence. Schools should pay high attention to the professional development of teachers. While deciding on activities, schools should ask about the opinions of teachers as well. The needs of teachers should be determined together and activities should be designed to meet their needs. It should be noted that, professional development programs are necessary for teachers, students and schools.

\section{Limitations of the Study}

The study was conducted including some private and public EFL teachers in Erbil, Moreover, a great number of the participants were Kurdish. In order to obtain more reliable results another study in which more international teachers are involved is a need. Also, the same study should be conducted in other cities of the country or even in other countries so that a comparison could be made. Only EFL teachers participated in the study. The same study should be conducted with other teachers from different fields. Due to these reasons, it is hard to generalize the findings for wider populations.

\section{References}

Ali, M. (2002). Using a suggested model of reflective practice for the professional development of EFL teaching practice advisors. Journal of Education College, 40.

Al-Mekhlafi, A. (2007). The development of prospective EFL teachers' specialist language competencies in UAE universities. University of Sharjah Journal for Shari'a Sciences \& Humanities, 4(1), $1-27$.

Badawi, M.F. (2009). Using blended learning for enhancing EFL prospective teachers' pedagogical knowledge and performance. Online Submission.

Birman, B.F., Desimone, L., Porter, A.C., \& Garet, M.S. (2000). Designing professional development that works. Educational leadership, 57(8), 28-33.

Brown, J. D., \& Rodgers, T. S. (2002). Doing second language research. Oxford: Oxford University Press.

Butler, Y.G. (2005). Comparative perspectives towards communicative activities among elementary school teachers in South Korea, Japan and Taiwan. Language Teaching Research, 9(4), 423446.

Butler, Y.G. (2015). English language education among young learners in East Asia: A review of current research (2004-2014). Language Teaching, 48(3), 303-342.

Chen, C.W.Y., \& Cheng, Y.S. (2010). A case study on foreign English teachers' challenges in Taiwanese elementary schools. System, 38(1), 41-49.

Chou, C-H. (2008). Exploring elementary English teachers' practical knowledge: A case study of EFL teachers in Taiwan. Asia Pacific Education Review, 9 (4), 529-541.

Copland, F., \& Garton, S. (2014). Key themes and future directions in teaching English to young learners: introduction to the Special Issue. ELT journal, 68(3), 223-230. 
Craft, A. (2000). Continuing professional development: A practical guide for teachers and schools (2nd ed.). London: Routledge.

Davis, J., \& Osborn, T. A. (2003). The language teacher's portfolio: A guide for professional development. Westport: Praeger.

Enever, J. (2014). Primary English teacher education in Europe. ELT journal, 68(3), 231-242.

England, L. (1998). Promoting Effective Professional Development in English Language Teaching (ELT). In Forum (Vol. 36, No. 2, p. n2). http://e.usia.gov/forum/.

Fletcher, M.A., \& Zuber-Skerritt, O., 2008. Professional development through action research: Case examples in South African higher education. Systemic Practice and Action Research, 21(1), 73-96.

Garton, S., \& Copland, F. (2015). Teaching English to Young Learners in Europe: Teachers' attitudes and perspectives. Attitudes towards English in Europe, 2, 321.

Hakim, S., \& Adams, R.D. (1965). The special clinical problem of symptomatic hydrocephalus with normal cerebrospinal fluid pressure: observations on cerebrospinal fluid hydrodynamics. Journal of the Neurological Sciences, 2(4), 307-327.

Halim, S.M.A. (2008). The Effect of Using Some Professional Development Strategies on Improving the Teaching Performance of English Language Student Teacher at the Faculty of Education, Helwan University in the Light of Pre-Service Teacher Standards. Online Submission.

Hargreaves, A., \& Fullan, M.G., 1992. Understanding teacher development. Teachers College Press, 1234 Amsterdam Avenue, New York, NY 10027.

Kabilan, M.K., \& Veratharaju, K., 2013. Professional development needs of primary school Englishlanguage teachers in Malaysia. Professional Development in Education, 39(3), 330-351.

Mart, Ç.T. (2012). Developing speaking skills through reading. International Journal of English Linguistics, 2 (6), 91-96.

Mart, Ç.T. (2013a). A passionate teacher: Teacher commitment and dedication to student learning. International Journal of Academic Research in Progressive Education and Development, 2(1), 437-442.

Mart, Ç.T. (2013b). Commitment to school and students. International Journal of Academic Research in Business and Social Sciences, 3(1), 336-340.

Mart, Ç.T. (2018). From communicative competence to language development. International Journal of English Linguistics, 8(2), 163-167.

Martinet, M.A., Gauthier, C., \& Raymond, D. (2001). Teacher training: Orientations, professional competencies. Education Québec.

Maykut, P.S., \& Morehouse, R. (1994). Beginning qualitative research: A philosophic and practical guide (Vol. 6). Psychology Press.

Millrood, R. (1999). How native English speakers can be better English teachers in Russia. The Internet TESL Journal, 5(1), 156-167.

Öztaş, A., Özdemir, M., \& Mart, Ç.T. (2017). Perspectives on quality assurance in higher education in Iraq: A case study at Ishik University. International Journal of Academic Research in Business and Social Sciences, 7(9), 268-272.

Qian, X., Tian, G., \& Wang, Q. (2009). Codeswitching in the primary EFL classroom in China-Two case studies. System, 37(4), 719-730.

Rahimi, M. (2008). What do we want teaching-materials for in EFL teacher training programs? Asian EFL Journal, 31(1), 1-35.

Rodgers, T.S. (2001). Language teaching methodology. ERIC Issue Paper. 
Ur, P. (2002). The English teacher as professional. In J. C. Richards \& W. A. Renandya (Eds.), Methodology in language teaching: An anthology of current practice (pp. 388-392).

Cambridge: Cambridge University Press.

Vernez, G., Culbertson, S., \&Constant, L. (2014). Strategic priorities for improving access to quality education in the Kurdistan Region--Iraq. Monograph. RAND Corporation. PO Box 2138, Santa Monica, CA 90407-2138.

Wang, L. (2010). An investigation of the current state of college teachers' teaching quality and teacher development. Asian EFL Journal, 12(1), 261-284.

Zhao, B. (2009). Corrective feedback and learner uptake in primary school EFL classrooms in China. Journal of Asia TEFL, 6(3).

Zhou, J. (1999). How can a Chinese teacher of English succeed in oral English classes? The Internet TESL Journal, 5(7). 